\title{
Impact of Therapy on Recovery during Rehabilitation in Patients with Traumatic Spinal Cord Injury
}

\author{
Catherine Truchon, 'Nader Fallah,, Argelio Santos, Joëlle Vachon, \\ Vanessa K. Noonan, and Christiana L. Cheng ${ }^{2}$
}

\begin{abstract}
Evidence-based planning of rehabilitation interventions is important to improving cost efficiency while maintaining patient and system outcomes. This article aims to explore the relationship between rehabilitation therapy, functional outcome, bed utilization, and care costs after traumatic spinal cord injury (tSCI). A retrospective review of 262 persons with tSCI admitted to an inpatient rehabilitation facility from 2005-2012 was conducted. Treatment variables and outcome measures included rehabilitation length of stay (LOS), days to rehabilitation (onset), hours and intensity of therapy, and Functional Independence Measure (FIM). Polynomial regression models and generalized additive models were applied to explore the relationship between therapy hours and motor FIM change. Simulation modeling was used to assess the impact of hypothetically increasing therapy intensity. Patients were grouped by injury as: C1-4 American Spinal Injury Association (ASIA) Impairment Scale (AIS) A,B,C; C5-8 AIS A,B,C; T1-S5 AIS A,B,C; and AIS D. The sample was 85\% male, mean age 45.9, median LOS 102 days, and mean therapy intensity $5.7 \mathrm{~h} /$ week. Motor FIM change was positively associated with total hours of therapy $(\beta=0.40, p<0.0001)$ up to a certain time point, adjusted for age, gender, injury, complications, and rehabilitation onset. Hypothetically increasing therapy intensity by 50\% and $100 \%$ resulted in average motor FIM efficiency gain ranging between $0.04-0.07$ and $0.1-0.17$, respectively, across injury groups. The hypothetical changes resulted in reductions in the average LOS and bed utilization rate, translating to cost savings of $\$ 20,000$ and $\$ 50,000$ (2011 CAD) for the $+50 \%$ and $+100 \%$ scenarios, respectively. The results highlight the importance of monitoring functional change throughout rehabilitation after tSCI and the need for customized therapeutic strategies.
\end{abstract}

Keywords: FIM efficiency; functional recovery; rehabilitation; simulation modeling; spinal cord injury

\section{Introduction}

$\mathbf{S}^{\mathrm{n}}$ TRATEGIC AND EVIDENCE-BASED PLANNING of rehabilitation interventions is of prime importance to improve cost efficiency while maintaining patient and system outcomes in these times of increasing economic pressure. ${ }^{1}$ Considerable research effort has been made to delineate which rehabilitation processes are effective and are most associated with positive patient outcomes. Most studies focus on the patient's functional outcome as measured by the Functional Independence Measure $\left(\mathrm{FIM}^{\circledR}\right)$ and employ FIM gain per day (FIM efficiency) to describe rehabilitation efficiency.

For spinal cord injury (SCI), functional recovery gained from rehabilitation is strongly determined by patient and injury characteristics $^{2-5}$ with some influence from the rehabilitation process. The recent SCIRehab Project conducted the first comprehensive quantification of the SCI inpatient rehabilitation process collecting ex- tensive patient and rehabilitation service data over a five-year period. ${ }^{6}$ The study carefully examined the relationships between rehabilitation services and outcomes, and revealed that more time in the rehabilitation disciplines of occupational therapy (OT) and physical therapy (PT) is positively associated with functional recovery, with a stronger effect observed within functionally homogenous patient grouping. ${ }^{7,8}$ Increasing the intensity at which the therapy is provided has also been shown to improve efficiency and patient functional outcomes in SCI and other impairments. ${ }^{9-13}$

The positive relationship between rehabilitation therapies and functional outcome, however, remains to be substantiated, because contrasting results from earlier studies have demonstrated a lack of benefit from therapy highlighting the fact that outcomes are influenced by a complicated multitude of demographic, clinical, and environmental factors. ${ }^{3,14}$ A better understanding of this relationship would help inform how therapies should be modulated to optimize patient outcomes.

\footnotetext{
${ }^{1}$ Institut national d'excellence en santé et en services sociaux, Québec City, Québec, Canada.

${ }^{2}$ Rick Hansen Institute, Vancouver, British Columbia, Canada.

${ }^{3}$ Institut de réadaptation en déficience physique de Québec, Québec City, Québec, Canada.

(c) Catherine Truchon et al., 2017; Published by Mary Ann Liebert, Inc. This Open Access article is distributed under the terms of the Creative Commons Attribution Noncommercial License (http://creativecommons.org/licenses/by-nc/4.0/) which permits any noncommercial use, distribution, and reproduction in any medium, provided the original author(s) and the source are credited.
} 
There is currently little known concerning the impact of rehabilitation therapies on system outcomes such as financial and resources requirements, other than the commonly used measure of length of stay (LOS) as a proxy. For SCI, the care continuum spans over multiple phases (e.g., pre-hospital, acute, rehabilitation, community), and any decisions made about a rehabilitation program can impact phases of care both upstream and downstream along the continuum. To assess such complex system questions, computer simulation models have been used to optimize management strategies and improve decision-making for a variety of difficult public health problems including health system capacity to deal with the changing SCI epidemiology, ${ }^{15}$ and with chronic disease, ${ }^{16}$ infectious disease epidemiology, ${ }^{17}$ patient journey modeling, ${ }^{18}$ diabetes treatment strategies, ${ }^{19}$ and secondary complications in SCI. ${ }^{20}$

In this study, a simulation model that comprises all phases of the typical traumatic SCI (tSCI) healthcare delivery system in Canada $^{21,22}$ was used to investigate the potential impact of rehabilitation therapy on system outcomes. For this application, we first evaluated the impact of inpatient rehabilitation therapy in the specific disciplines of OT, PT, and kinesiology on motor functional change and determined the predictors for motor function change. These real patient results were then fed into the simulation model to examine the impact of a hypothetical practice change of higher therapy intensity on system outcomes. This study aimed to increase our understanding of the relationship between rehabilitation and functional outcome, as well as the effects on resource implication-specifically bed utilization and its associated care costs.

\section{Methods}

\section{Study design}

This is a retrospective study based on records of 323 patients with tSCI admitted to the inpatient rehabilitation facility at l'Institut de Réadaptation en Déficience Physique de Québec (IRDPQ) (the study site) in Québec City, Québec, Canada, between the periods of April 8, 2005 and March 24, 2012 (Fig. 1). The study site and its partner, the Centre Hospitalier Universitaire de Québec-Hôpital de l'Enfant-
Jésus, constitute the Centre of Expertise for patients with SCI in eastern Québec, providing care in seven regions of the province. As SCI Centre of Expertise, policies are in place to facilitate timely admission for patients requiring care. The study site enrolled all adult patients with tSCI except for those requiring ventilator support (patients with a C1-C3 American Spinal Injury Association [ASIA] Impairment Scale [AIS] A) who would be admitted to a dedicated facility elsewhere in the province; consequently the analysis lacked representation from this injury group. Data source for the study was from the two different local administrative databases used by the study site: CliniBase and a local Access database. Institutional research ethics approval was obtained before study commencement.

\section{Study variables}

Patient and injury factors included age at injury, gender, mechanism of injury, days from injury to rehabilitation admission (rehabilitation onset), presence of complications (pressure ulcer, urinary tract infection, and pneumonia), and neurological classification at admission (C1-4 AIS A,B,C; C5-8 AIS A,B,C; T1-S5 AIS A,B,C; and AIS D) as measured by the AIS from the International Standards of Neurological Classification of SCI (ISNCSCI). ${ }^{23}$

Therapy treatment factors included in this analysis were LOS at study site, hours of therapy, and therapy intensity. Total hours of therapy were defined as the time therapists spent working directly with a patient in an individual or group setting during the patient's LOS in the disciplines of OT, PT, and kinesiology. Because the measure collected pertains to the time provided by the therapistsas opposed to the time actually received by each individual patient - the hours of therapy may somewhat underestimate the actual therapy time each patient benefited from; intervention time provided by one therapist may be divided by more than one patient in certain group-intervention situations. Therapy intensity was defined as the hours of therapy provided by therapists per week and was calculated by the total hours of therapy provided divided by the total number of weeks of a patient's LOS.

At the study site, occupational therapists are responsible for teaching techniques for managing daily life activities and tasks such as getting dressed, preparing meals, and getting around the home and the community. The physical therapists help patients

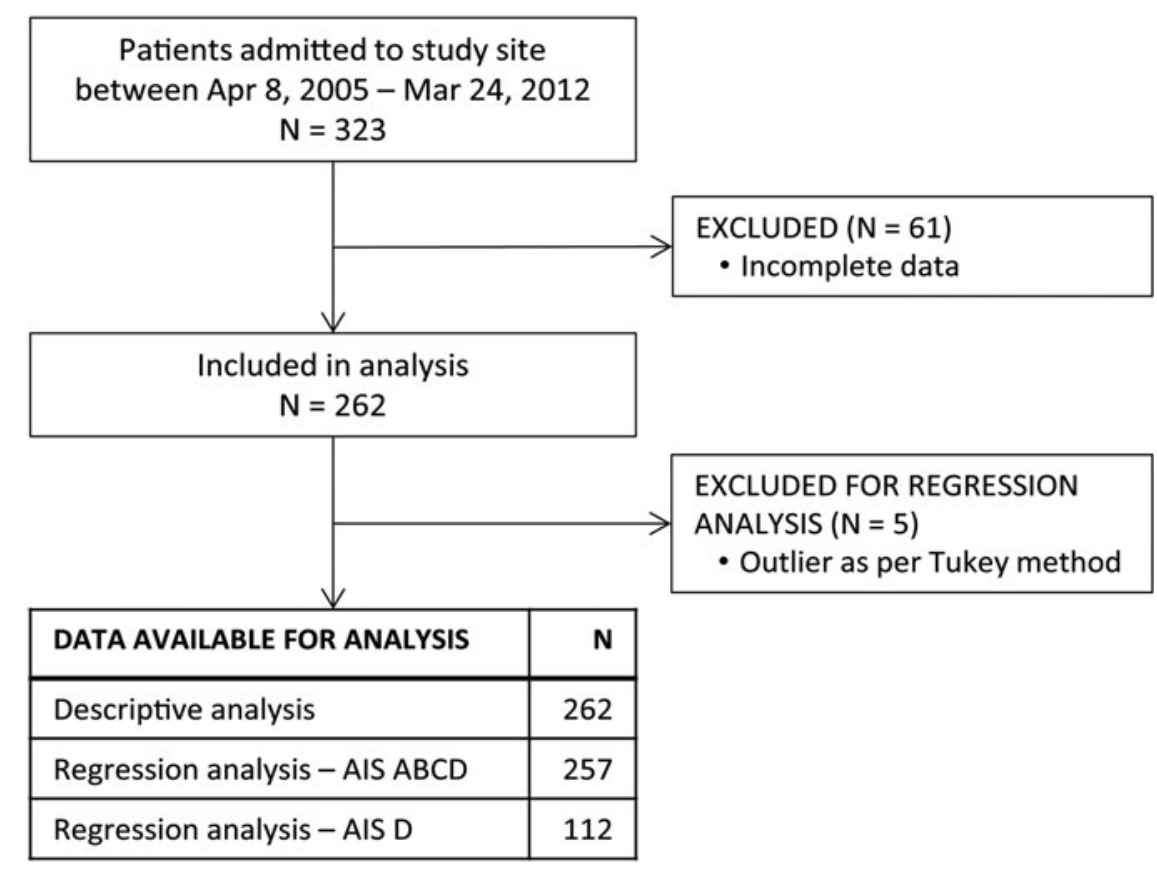

FIG. 1. Sample size flow chart of the study cohort. AIS, American Spinal Injury Association (ASIA) Impairment Scale. 
develop muscular potential and regain motor function. Patients are referred to kinesiologists by the physical therapist to work on movement and cardiovascular conditioning. The kinesiology therapies are typically delivered in a group-based format and thereby the "hours of therapy provided" data significantly underestimates the actual time spent by the patients with the kinesiologists. Moreover, kinesiology therapies began only a few weeks before discharge and would generally continue on an outpatient basis. These outpatient hours were not included in the reported total hours of therapy.

The outcome of this study was the Motor Function Scores from the FIM $^{1}$ (motor FIM). This measure was used to describe the impact of the SCI on patient's activities of daily living and function in terms of the degree of independence performing the activities; hence, it is considered as a valid measure for burden of care but not necessarily for the degree of disability. The change in motor FIM assessed at admission and at discharge was used to reflect the functional change during the rehabilitation stay. Motor Function Scores were assessed on a seven-level scale in which level one indicated a patient's complete dependence to perform a task and level seven indicated that a patient can perform a specific task with complete independence, yielding a range of Motor Function Scores from 13 (totally dependent) to 91 (totally independent). Motor FIM efficiency was defined as the total amount of change in motor FIM divided by the patient's LOS.

\section{Statistical analysis}

Descriptive analysis was performed to describe the patient sample. Before exploring the relationship between amount of rehabilitation therapy and motor FIM change, successive statistical tests involving a generalized additive model ${ }^{24}$ belonging to the nonparametric regression were first applied to determine the most suitable method of regression modeling for the data. The results suggested that quadratic form of regression was more appropriate for the data than a linear form (Supplementary Material; see online supplementary material at ftp.liebertpub.com). Accordingly, polynomial regression with linear and quadratic forms of total hours of therapy was then applied and assessed with the lack-of-fit criteria. The second-order regression model (quadratic form of total hours of therapy) was used to analyze the effect of the amount of therapy on motor FIM change. Factors considered as clinically and statistically relevant for motor FIM change were included in the model (age at injury, gender, AIS and level of injury at admission, complications, and rehabilitation onset). Year of injury was not considered, because the mean LOS and the mean motor FIM change were not statistically different throughout the study years. Mechanism of injury was deemed not as clinically relevant as AIS and level of injury.

Patients with an AIS D injury were modeled as a subgroup, because preliminary data analysis of the joint distribution of variables revealed a different pattern of motor FIM improvement from that group compared with the rest of the patients.

For the regression analyses, outliers were removed based on the Tukey method, which defines an outlier as 1.5 interquartile range below the 25 th percentile or above the 75 th percentile. A sensitivity analysis was performed to test whether the patient population with complete data was different from those with incomplete data. The Wilcoxon rank sum test was applied to compare the population means including age, motor FIM at admission, motor FIM change, complications, total hours of therapy, and total rehabilitation LOS.

A $p$ value of $<0.05$ was considered to be statistically significant. All statistical analyses were performed using IBM SPSS Statistics for Windows, Version 23.0, Armonk, NY, IBM Corp; R 3.1 (CRAN: the Comprehensive R Archive Network at cran.r-project.org/); and SAS software, Version 9.3 of the SAS System for Windows, ${ }^{\circ} 2013$, SAS Institute Inc., Cary, NC.

\section{Simulation modeling}

To explore ways to improve the efficiency of the provision of care and to predict its potential financial and resource implication, a computer simulation model referred to as the ACT Model V1.0 was employed. The development of the ACT Model has been described elsewhere. $^{21,22}$

The ACT Model was customized for the study site in the following ways: (1) the study site's data on patient, injury, and therapy characteristics were used as input; (2) motor FIM change was added as an outcome after the rehabilitation care phase; (3) statistical analyses performed in this study on the effect of amount of therapy on motor FIM change were also used as input.

The model was used to test the effects of hypothetically increasing therapy intensities on system outcomes. Three "what-if" scenarios chosen for comparative analysis were: (1) baseline scenario (i.e., current therapy intensity); (2) 50\% increase in therapy intensity; (3) $100 \%$ increase in therapy intensity. The simulation was designed to reflect the rehabilitation program in two aspects: the cumulative hours of therapy were increased gradually throughout the LOS, and the mean total hours of therapy provided was specific to each injury group. To satisfy these conditions, the simulation framework consisted of consecutive incremental steps of 15 therapy hours that were assigned to the four injury groups until each group reached its respective observed mean therapy hours, after which the group would be assigned the same number of hours until the end of simulation.

The assigned therapy hours were used to predict motor FIM change using the results found in this study. The assigned therapy hours were also used to predict LOS based on a linear regression model where both the number of therapy hours and injury severity were significant predictors.

To account for therapy intensity, the LOS was reduced to reflect each proposed scenario. For the $50 \%$ increase scenario, the LOS was reduced to $75 \%$, so that if $10 \mathrm{~h}$ of therapy were normally provided in 10 days, the simulation would adjust it to 7.5 days (i.e., providing $1.5 \mathrm{~h}$ of therapy every day instead of $1 \mathrm{~h}$ ). For the $100 \%$ scenario, the LOS was reduced to $50 \%$ (i.e., providing $2 \mathrm{~h}$ of therapy per day, instead of $1 \mathrm{~h}$ ).

The predicted motor FIM change and LOS were used to compute motor FIM efficiency. LOS was also used to calculate bed utilization and care costs. The bed utilization was calculated by the formula:

$$
\frac{\text { Rehab LOS for a period }}{\text { Available beds }}(\text { Number of days in a year }) * 100 \%
$$

Care costs were based on the values of cost per day and cost of services during the initial hospitalization for each neurological category of tSCI as published by Krueger and colleagues, ${ }^{25}$ and were reported as 2011 Canadian dollars. Fifty replications were performed for each simulation run.

\section{Results}

\section{Patient, injury, therapy and outcome characteristics}

Patient and injury characteristics are presented in Table 1 for each of the four neurological groups and for the total sample. Of the 262 patients with tSCI, the median age at injury was 46 years and $85 \%$ were men. The top two mechanisms of injury were transportrelated $(39 \%)$ and falls $(38 \%)$. The duration from injury to rehabilitation admission was shortest for patients in AIS D group (16 days) and longest for those in C5-8 AIS A,B,C group (41 days). The $\mathrm{C} 1-4$ and $\mathrm{C} 5-8$ AIS A,B,C groups had a relatively narrow range (95\% confidence interval $[\mathrm{CI}]$ ) of motor FIM at admission compared with that at discharge; conversely, the AIS D group had a wide range of motor FIM on admission and a slimmer range at discharge. Thirty-five percent of patients had pressure ulcers; 52\% had urinary tract infections; and $8 \%$ had pneumonia.

Therapy characteristics and motor FIM efficiency are presented in Table 2. On average, occupational therapists provided $53.3 \pm 41.2 \mathrm{~h}$ 
Table 1. Patient and Injury Characteristics by Injury Group

\begin{tabular}{|c|c|c|c|c|c|}
\hline \multirow[b]{2}{*}{ Characteristics } & \multicolumn{4}{|c|}{ Neurological injury group } & \multirow[b]{2}{*}{ Total } \\
\hline & $C 1-4$ AIS A,B,C & $C 5-8$ AIS A,B,C & T1-S5 AIS A,B,C & $A I S D$ & \\
\hline Sample size; n $(\%)$ & $34(13)$ & $38(14)$ & $78(30)$ & $112(42)$ & $262(100)$ \\
\hline Age at injury; median (min, $\max )$ & $50.3(16.3,80.4)$ & $39.1(18.4,81.5)$ & $37.2(17.6,76.2)$ & $49.7(15.6,87.2)$ & $45.9(15.6,87.2)$ \\
\hline Gender (male, \%) & 94.1 & 84.2 & 79.5 & 86.6 & 85.2 \\
\hline \multicolumn{6}{|l|}{ Mechanism of injury; n (\%) } \\
\hline Transport & $14(5.3)$ & $20(7.6)$ & $36(13.7)$ & $32(12.2)$ & $102(38.9)$ \\
\hline Falls & $15(5.7)$ & $10(3.8)$ & $22(8.4)$ & $52(19.8)$ & $99(37.8)$ \\
\hline Sport & $5(1.9)$ & $5(1.9)$ & $14(5.3)$ & $16(6.1)$ & $40(15.3)$ \\
\hline Assault & $0(0)$ & $1(0.4)$ & $0(0)$ & $2(0.8)$ & $3(1.1)$ \\
\hline $\begin{array}{l}\text { Days from injury to rehabilitation } \\
\text { admission; median }(95 \% \mathrm{CI})\end{array}$ & $34.5(25.4,42)$ & $41(31,47)$ & $19(16,23)$ & $16(14,18)$ & $20.5(18,23)$ \\
\hline $\begin{array}{l}\text { Admission motor FIM score; } \\
\text { mean (SD) }\end{array}$ & $13.6(2.1)$ & $18.7(5.6)$ & $32.8(10.5)$ & $48.6(23)$ & $35.1(21)$ \\
\hline median $(95 \% \mathrm{CI})$ & $13(13,13)$ & $18(14,21)$ & $31(29,33)$ & $49.5(40,57)$ & $30(26,32)$ \\
\hline $\begin{array}{l}\text { Discharge motor FIM score; } \\
\text { mean (SD) }\end{array}$ & $37.3(27)$ & $48.8(19.7)$ & $74.6(12.4)$ & $80.3(12.2)$ & $68.4(22.7)$ \\
\hline median $(95 \% \mathrm{CI})$ & $23.5(18,42)$ & $46(35,60)$ & $77(75,78)$ & $84(83,86)$ & $77.5(76,79)$ \\
\hline Pressure ulcer; n $(\%)$ & $22(64.7)$ & $24(63.1)$ & $31(39.7)$ & $15(13.4)$ & $92(35.1)$ \\
\hline Urinary tract infection; $\mathrm{n}(\%)$ & $26(76.5)$ & $27(71.1)$ & $53(67.9)$ & $30(26.8)$ & $136(51.9)$ \\
\hline Pneumonia; n (\%) & $8(23.5)$ & $6(15.7)$ & $1(1.3)$ & $5(4.5)$ & $20(7.6)$ \\
\hline
\end{tabular}

AIS, American Spinal Injury Association (ASIA) Impairment Scale; CI, confidence interval; FIM, Functional Independence Measure; SD, standard deviation.

of OT, physical therapists provided $41.2 \pm 36.4 \mathrm{~h}$ of PT, and $7.5 \pm$ $7.2 \mathrm{~h}$ of therapy to those who received kinesiology treatment. Therapists provided the least amount of therapy to the AIS D group and the most to the C5-8 AIS A,B,C group. The mean direct therapy intensity was $3.0,2.4$, and $0.4 \mathrm{~h}$ per week for OT, PT, and kinesiology, respectively, giving a mean total $5.7 \mathrm{~h}$ of direct therapy per week in these three disciplines. The mean rehabilitation LOS is $122 \pm 89$ days. The mean total motor FIM efficiency was $0.18,0.17$, 0.41 , and 0.58 for group C1-4 AIS A,B,C, C5-8 AIS A,B,C, T1-S5 AIS A,B,C, and AIS D, respectively.

The sensitivity analysis revealed that patients who were excluded from the analysis because of incomplete data had significantly higher admission motor FIM (46.7 vs. 35.1, $p=0.002$ ), fewer total hours of therapy (OT, PT, and kinesiology) $(61 \mathrm{~h}$ vs. $100 \mathrm{~h}$, $p<0.0001$ ), and shorter rehabilitation LOS (96 days vs. 122 days, $p=0.02$ ) than those included in the analysis. Age at injury, complications, and motor FIM change were not significantly different between the two groups.

\section{Effect of hours of therapy on motor FIM change}

To investigate the effect of total hours of therapy (THT) on motor FIM change, polynomial regression modeling with the quadratic form of total hours of therapy $\left(\mathrm{THT}+\mathrm{THT}^{2}\right)$ was applied. Outliers as per Tukey method $(n=5)$ were removed from the modeling. In the model with all injury groups included, AIS A

Table 2. Therapy Characteristics and Motor Functional Independence Measure Efficiency by Injury Group

\begin{tabular}{|c|c|c|c|c|c|}
\hline \multirow[b]{2}{*}{ Therapy characteristics } & \multicolumn{4}{|c|}{ Neurological injury group } & \multirow[b]{2}{*}{ Total } \\
\hline & $C 1-4$ AIS $A, B, C$ & $C 5-8$ AIS A,B,C & $T-S 5 A I S A, B, C$ & $A I S D$ & \\
\hline Occupational therapy, sample size & 34 & 38 & 78 & 109 & 259 \\
\hline total hours; mean (SD) & $93.2(50.2)$ & $100.4(39.5)$ & $46.3(21.9)$ & $30.4(23.5)$ & $53.3(41.2)$ \\
\hline Physical therapy, sample size & 34 & 38 & 78 & 109 & 259 \\
\hline total hours; mean (SD) & $79.8(43.2)$ & $77.0(31.6)$ & $34.1(26.2)$ & $22.5(22.5)$ & $41.2(36.4)$ \\
\hline Kinesiology, sample size & 23 & 34 & 75 & 82 & 214 \\
\hline total hours; mean (SD) & $9.9(6.6)$ & $11.3(8.3)$ & $8.1(8.0)$ & $4.8(4.6)$ & $7.5(7.2)$ \\
\hline $\begin{array}{l}\text { Total hours of therapy (OT, PT, Kins); } \\
\text { mean (SD) }\end{array}$ & $179.7(91.7)$ & $187.6(67.6)$ & $88.2(43.9)$ & $56(45.2)$ & $100.4(77.5)$ \\
\hline Occupational therapy; hours per week & 3.2 & 3.2 & 2.7 & 3.0 & 3.0 \\
\hline Physical therapy; hours per week & 2.8 & 2.5 & 2.0 & 2.2 & 2.4 \\
\hline Kinesiology; hours per week & 0.3 & 0.4 & 0.5 & 0.5 & 0.4 \\
\hline $\begin{array}{l}\text { Total hours of therapy (OT, PT, Kins) } \\
\text { per week }\end{array}$ & 6.3 & 6.1 & 5.2 & 5.6 & 5.7 \\
\hline Length of stay; mean (SD) & $201.1(103)$ & $216.6(93.8)$ & $119.7(52.2)$ & $70.1(55.1)$ & $122.4(89.25)$ \\
\hline Motor FIM efficiency; mean (SD) & $0.18(0.3)$ & $0.17(0.1)$ & $0.41(0.3)$ & $0.58(0.4)$ & $0.42(0.4)$ \\
\hline
\end{tabular}

AIS, American Spinal Injury Association (ASIA) Impairment Scale; SD, standard deviation; OT, occupational therapy; PT, physical therapy; Kins, kinesiology; FIM, Functional Independence Measure. 
$(\beta=-11, p=0.002)$, AIS B $(\beta=-12, p=0.01)$, high cervical injuries $(\beta=-11, p<0.001)$, and pneumonia $(\beta=-8.7, p=0.05)$ were found to have significant negative associations with motor FIM change (Table 3). None of the variables were significant in the AIS D model except for the variable of total hours of therapy (Table 4).

When modeling the linear and quadratic forms of total hours of therapy provided, the results revealed that even though therapy hours had a positive effect on motor FIM change $(\beta=0.40$, $p<0.0001)$, this relationship would not last infinitely as indicated by the negative estimate from its quadratic form $(\beta=-0.001$, $p<0.0001)$. Similar results were observed in the AIS D group (Table 4) where the nonlinear effect of hours of therapy on motor FIM change was found to be stronger for the AIS D group than the whole sample ( $\beta=0.61$ vs. $\beta=0.40$ ).

\section{Simulation scenario - increasing intensity of rehabilitation therapy}

The amount of rehabilitation therapy provided to patients with SCI is highly dependent on injury characteristics; however, within the same rehabilitation plan, the therapy can be provided at dif-

Table 3. Polynomial Regression Model to Explore THE IMPACT OF HOURS OF THERAPY ON MOTOR FunCTIONAL IndePendence Measure Change for American Spinal InJury Association ImPairment Scale A,B,C,D Groups

\begin{tabular}{|c|c|c|c|c|}
\hline \multirow[b]{2}{*}{$\begin{array}{l}\text { Independent } \\
\text { variable }\end{array}$} & \multicolumn{4}{|c|}{ Outcome-Motor FIM change } \\
\hline & Estimate & $\begin{array}{l}\text { Std. } \\
\text { error }\end{array}$ & $\begin{array}{l}95 \% \\
\text { Wald CI }\end{array}$ & $\mathrm{p}$ \\
\hline Intercept & 19.41 & 7.37 & $4.97,33.86$ & 0.008 \\
\hline Age at injury & -0.05 & 0.06 & $-0.17,0.07$ & 0.412 \\
\hline $\begin{array}{l}\text { Gender } \\
\text { Female } \\
\text { Male (reference) }\end{array}$ & $\begin{array}{l}1.34 \\
-\end{array}$ & $\begin{array}{r}3.08 \\
-\end{array}$ & $\begin{array}{c}-4.71,7.39 \\
-\end{array}$ & $\begin{array}{c}0.664 \\
-\end{array}$ \\
\hline $\begin{array}{l}\text { ASIA Impairment Sca } \\
\text { AIS A } \\
\text { AIS B } \\
\text { AIS C } \\
\text { AIS D (reference) }\end{array}$ & $\begin{array}{c}\text { ale (AIS) } \\
-11.11 \\
-11.62 \\
3.41 \\
-\end{array}$ & $\begin{array}{r}3.61 \\
4.54 \\
3.59 \\
-\end{array}$ & $\begin{array}{c}-18.19,-4.03 \\
-20.51,-2.73 \\
-3.62,10.44 \\
-\end{array}$ & $\begin{array}{l}\mathbf{0 . 0 0 2} \\
\mathbf{0 . 0 1 0} \\
0.341 \\
-\end{array}$ \\
\hline $\begin{array}{l}\text { Neurological level of } \\
\text { C1-4 } \\
\text { C5-8 } \\
\text { T1-S5 (reference) }\end{array}$ & $\begin{array}{c}\text { injury } \\
-10.90 \\
-4.53 \\
-\end{array}$ & $\begin{array}{r}3.07 \\
3.12 \\
-\end{array}$ & $\begin{array}{c}-16.92,-4.88 \\
-10.64,1.59 \\
-\end{array}$ & $\begin{array}{c}<\mathbf{0 . 0 0 0} \\
0.147 \\
-\end{array}$ \\
\hline $\begin{array}{l}\text { Pressure ulcer } \\
\text { Yes } \\
\text { No (reference) }\end{array}$ & $\begin{array}{c}2.33 \\
-\end{array}$ & $\begin{array}{r}2.70 \\
-\end{array}$ & $\begin{array}{c}-2.97,7.64 \\
-\end{array}$ & $\begin{array}{c}0.388 \\
-\end{array}$ \\
\hline $\begin{array}{l}\text { Urinary tract infection } \\
\text { Yes } \\
\text { No (reference) }\end{array}$ & $\begin{array}{c}2.18 \\
-\end{array}$ & $\begin{array}{r}2.53 \\
-\end{array}$ & $\begin{array}{c}-2.78,7.13 \\
-\end{array}$ & $\begin{array}{c}0.390 \\
-\end{array}$ \\
\hline $\begin{array}{l}\text { Pneumonia } \\
\text { Yes } \\
\text { No (reference) }\end{array}$ & $\begin{array}{c}-8.67 \\
-\end{array}$ & $\begin{array}{r}4.39 \\
-\end{array}$ & $\begin{array}{c}-17.27,-0.08 \\
-\end{array}$ & $\begin{array}{c}0.048 \\
-\end{array}$ \\
\hline Rehabilitation onset & -0.04 & 0.02 & $-0.09,0.008$ & 0.105 \\
\hline $\begin{array}{l}\text { Total hours of } \\
\text { therapy - linear }\end{array}$ & 0.40 & 0.06 & $0.27,0.53$ & $<0.0001$ \\
\hline $\begin{array}{l}\text { Total hours of } \\
\text { therapy - quadratic }\end{array}$ & -0.001 & 0.0002 & $-0.002,-0.001$ & $<0.0001$ \\
\hline
\end{tabular}

Rehabilitation onset is defined as the days from injury to rehabilitation admission. FIM, Functional Independence Measure; Std. error, standard error; CI, confidence interval; ASIA, American Spinal Injury Association.
Table 4. Polynomial Regression Model to Explore THE IMPACT OF HOURS OF THERAPY ON MOTOR FunCTIONAL IndePendence Measure Change for American Spinal Injury Association Impairment Scale D Group

\begin{tabular}{|c|c|c|c|c|}
\hline \multirow[b]{2}{*}{$\begin{array}{l}\text { Independent } \\
\text { variable }\end{array}$} & \multicolumn{4}{|c|}{ Outcome-Motor FIM change } \\
\hline & Estimate & $\begin{array}{l}\text { Std. } \\
\text { error }\end{array}$ & $\begin{array}{c}95 \% \\
\text { Wald CI }\end{array}$ & $\mathrm{p}$ \\
\hline Intercept & 5.44 & 11.66 & $-17.41,28.30$ & 0.641 \\
\hline Age at injury & -0.04 & 0.09 & $-0.21,0.13$ & 0.641 \\
\hline $\begin{array}{l}\text { Gender } \\
\text { Female } \\
\text { Male (reference) }\end{array}$ & $\begin{array}{c}5.41 \\
-\end{array}$ & $\begin{array}{c}4.58 \\
-\end{array}$ & $\begin{array}{c}-3.56,14.39 \\
-\end{array}$ & $\begin{array}{c}0.237 \\
-\end{array}$ \\
\hline $\begin{array}{l}\text { Neurological level of } \\
\text { C1-4 } \\
\text { C5-8 } \\
\text { T1-S5 (reference) }\end{array}$ & $\begin{array}{c}\text { injury } \\
-7.00 \\
0.56 \\
-\end{array}$ & $\begin{array}{c}4.24 \\
4.35 \\
-\end{array}$ & $\begin{array}{c}-15.30,1.30 \\
-7.97,9.09 \\
-\end{array}$ & $\begin{array}{c}0.098 \\
0.898 \\
-\end{array}$ \\
\hline $\begin{array}{l}\text { Pressure ulcer } \\
\text { Yes } \\
\text { No (reference) }\end{array}$ & $\begin{array}{c}1.95 \\
-\end{array}$ & $\begin{array}{c}4.89 \\
-\end{array}$ & $-7.64,11.53$ & $\begin{array}{c}0.690 \\
-\end{array}$ \\
\hline $\begin{array}{l}\text { Urinary tract infection } \\
\text { Yes } \\
\text { No (reference) }\end{array}$ & $\begin{array}{c}2.78 \\
-\end{array}$ & $\begin{array}{c}3.98 \\
-\end{array}$ & $-5.02,10.58$ & $\begin{array}{c}0.485 \\
-\end{array}$ \\
\hline $\begin{array}{l}\text { Pneumonia } \\
\text { Yes } \\
\text { No (reference) }\end{array}$ & $\begin{array}{c}-7.16 \\
-\end{array}$ & $\begin{array}{c}7.88 \\
-\end{array}$ & $\begin{array}{c}-22.61,8.28 \\
-\end{array}$ & $\begin{array}{c}0.363 \\
-\end{array}$ \\
\hline Rehabilitation onset & 0.00 & 0.03 & $-0.06,0.06$ & 0.994 \\
\hline $\begin{array}{l}\text { Total hours } \\
\text { of therapy - linear }\end{array}$ & 0.61 & 0.11 & $0.39,0.84$ & $<0.0001$ \\
\hline $\begin{array}{l}\text { Total hours } \\
\text { of therapy - } \\
\text { quadratic }\end{array}$ & -0.002 & 0.001 & $-0.003,-0.001$ & $<0.0001$ \\
\hline
\end{tabular}

Rehabilitation onset is defined as the days from injury to rehabilitation admission. FIM, Functional Independence Measure; Std. error, standard error; CI, confidence interval.

ferent intensities. An important question is how different intensities of therapy impact key performance metrics and outcomes in the system and in the patient's recovery.

In the simulation analysis, increasing the therapy intensity resulted in higher motor FIM efficiency as illustrated by the absolute difference of the motor FIM efficiency between the baseline scenario and the scenario of $50 \%$ (Fig. 2a) or $100 \%$ (Fig. 2b) increased intensity. The gain in motor FIM efficiency was consistent over the course of the simulation where additions of 15 therapy hours were assigned at each run/step until the actual average therapy hours were reached. For example, there was an increase in motor FIM efficiency with as little as 15 hours of therapy and with as much as 180 hours of therapy for patients in the C1-4 AIS A,B,C group. For the AIS D group, increasingly higher motor FIM efficiency was achieved with more hours of therapy for both the $50 \%$ and $100 \%$ intensity increase scenarios.

Under the $50 \%$ intensity increase scenario, the average gain in motor FIM efficiency was similar for all injury groups with 0.04, 0.05, 0.05 , and 0.07 for the injury groups $\mathrm{C} 1-4$ AIS A,B,C, C5-8 AIS A,B,C, T1-S5 AIS A,B,C, and AIS D, respectively. Under the $100 \%$ intensity increase scenario, the gain in motor FIM efficiency was the smallest for the $\mathrm{C} 1-4$ AIS A,B,C group with an average of 0.1 , and 0.14 for C5-8 AIS A,B,C and T1-S5 AIS A,B,C groups; an increasing gain was observed for the AIS D group with an average of 0.17 . 

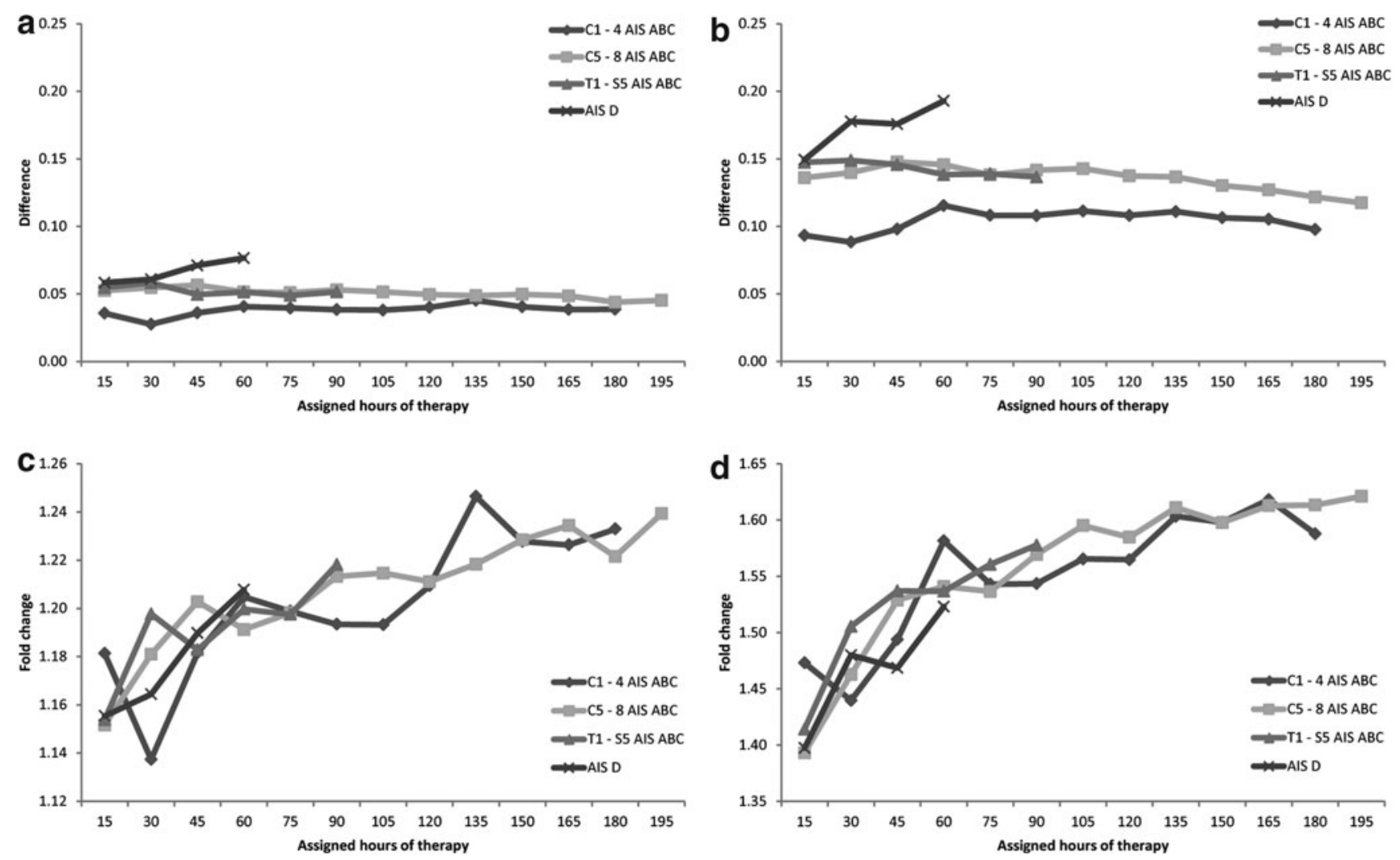

FIG. 2. Impact of increasing therapy intensity on motor Functional Independence Measure (FIM) efficiency. Absolute difference of motor FIM efficiency between baseline and simulation scenario of 50\% increase (a), and 100\% increase (b). Relative difference (fold change) of motor FIM efficiency between baseline and scenario 50\% increase (c), and 100\% increase (d). AIS, American Spinal Injury Association (ASIA) Impairment Scale.

To emphasize the gain in motor FIM efficiency by adjusting for the baseline motor FIM efficiency, we examined the fold change (the ratio of scenario over baseline). Even though the change in absolute value was similar throughout the simulation, the fold change actually increased with more hours of therapy for all injury groups in both the scenarios of $50 \%$ therapy intensity increase (Fig. 2c) and $100 \%$ increase (Fig. 2d). The rate at which the fold change increased was similar for all injury groups, including the C1-4 AIS A,B,C group, whose absolute change was small but its fold change was comparable to that of other groups.

Compared with the baseline scenario, the average rehabilitation LOS had decreased by an overall of 30 and 60 days for the scenarios with $50 \%$ and $100 \%$ increase in therapy intensity, respectively. The baseline scenario also consistently used more beds with a utilization rate of $80 \%$ compared with rates of $17 \%$ and $30 \%$ in the $50 \%$ and $100 \%$ increase scenarios, respectively. According to the simulation analysis, the reduction in LOS and bed utilization observed in the respective scenarios would translate to savings of $\$ 20,000$ and $\$ 50,000$ in care costs per patient (Table 5).

\section{Discussion}

This study provided evidence of the impact on the amount and the intensity of therapy on motor functional change and system outcomes as measured by motor FIM efficiency, LOS, bed utilization, and care costs. Using sophisticated statistical methodologies such as the generalized additive model and polynomial regression model, it was revealed that the amount of therapy in the disciplines of OT, PT, and kinesiology had a nonlinear positive relationship with motor functional change in that more therapy was associated with greater change until a certain time point. Other significant predictors of motor functional change were neurological severity and pneumonia. The observed benefits of therapy on patient functional outcome prompted the investigation of how varying the amount of therapy would impact system outcomes using a facility-specific computer simulation model. Increasing the amount of therapy by increasing the intensity translated into improved system efficiency, because the simulation analysis illustrated potential reduction in LOS and bed utilization leading to a corresponding savings in care costs.

\section{Relation to previous literature}

Models of care and modalities of service delivery are unique to each country or region that, together with varying patient

Table 5. Simulation Results on the Impact of InCREasing Therapy Intensity on System Outcomes

\begin{tabular}{|c|c|c|c|}
\hline \multirow[b]{2}{*}{ Simulation Output } & \multicolumn{3}{|c|}{$\begin{array}{l}\text { Scenario of increasing } \\
\text { therapy intensity }\end{array}$} \\
\hline & Baseline & $\begin{array}{l}50 \% \\
\text { Increase }\end{array}$ & $\begin{array}{l}100 \% \\
\text { Increase }\end{array}$ \\
\hline Rehabilitation LOS, mean & 167 days & 137 days & 107 days \\
\hline Rehabilitation bed utilization & $80 \%$ & $63 \%$ & $50 \%$ \\
\hline Care cost (CAD) & $\$ 180,000$ & $\$ 160,000$ & $\$ 130,000$ \\
\hline
\end{tabular}

LOS, length of stay; CAD, Canadian dollars. 
populations and different payment methods, may account for the inconsistency of findings between our study and those from previous studies. ${ }^{3,14}$ During rehabilitation, our patients were provided with a mean of $53 \mathrm{~h}$ and $41 \mathrm{~h}$ of direct services with OT and with PT over a mean LOS of 122 days contrasting with the similar amount of therapy provided in only 55.7 days reported by the SCIRehab project. ${ }^{6}$ In fact, the hypothetical increases in therapy intensity used in this study were in the range of that reported in SCIRehab. The reasons for the varying level of therapy observed between the two studies are beyond the scope of the current study. The Québec rehabilitation model, however, has a strong psychosocial service component providing patients with various social participation interventions that might have contributed to longer LOS.

The SCIRehab project reported that more PT or certain OT activities will yield higher discharge motor FIM score. ${ }^{6,7}$ Given the nature of the data in our study, it was not possible to examine the specific activities within each discipline or to examine each discipline individually; the hours of therapy in the three disciplines of OT, PT, and kinesiology were combined in our analysis. In addition, differences observed in the time from injury to rehabilitation admission, therapy hours provided, and LOS between the SCIRehab and our data highlight the differences in our system of care. According to data from the study site, patients with C1-4 AIS A,B,C and C5-8 AIS $\mathrm{A}, \mathrm{B}, \mathrm{C}$ took on average 10 and 20 days longer, respectively, to be admitted to rehabilitation from time of injury when compared with the same patient groups in SCIRehab, although the median for these two groups in our population was still around 30 days.

Despite the differences in the systems of care, our patient population reached and even exceeded their potential motor FIM change by specific injury level according to the expected functional scores published by the Paralyzed Veterans of America. ${ }^{26}$ As a result of the long LOS in our data, however, the motor FIM efficiency in our study was quite low ( 0.43 for all patients) compared with other recent SCI studies that reported a motor FIM efficiency of $0.7(n=30 \text {, rehabilitation } \operatorname{LOS}=36 \text { days })^{27}$ and $0.95(n=775$, rehabilitation $\operatorname{LOS}=51$ days). ${ }^{28}$

The expected functional level of independence a person with SCI will reach is strongly associated with the level and completeness of injury. ${ }^{29,30}$ The SCIRehab project showed that the impact of therapy on functional change became more evident when analyzing injury groups of similar neurological level. Consistent with this, our results showed a stronger effect of hours of therapy on motor FIM change in the injury group of AIS D than the entire patient population ( $\beta=0.6$ vs. $\beta=0.4$ ). The sample size of patients with AIS D was sufficient to model as a separate group but that of the other AIS levels (A,B,C) was not. Large variations still existed in terms of functional abilities (motor FIM score) as well as the hours of therapy received within the AIS D group; future study should explore methods to achieve a more homogenous group for analysis.

\section{Implications}

Nonlinear relationship. The nonlinear aspect of the relationship between hours of therapy and motor FIM change found in our study illustrates that therapy hours are positively associated with motor FIM change up to a certain time point, after which this relationship becomes negative. The negative portion does not imply that excessive therapy would reverse the motor FIM gained earlier; it should be interpreted that therapy is effective in improving motor FIM scores up to the point that likely coincides with the point where the expected functional outcome is reached. Given the physical limitation imposed by the injury, a patient's FIM score would not be expected to improve to the maximal score even if the patient were provided with an unlimited amount of therapy.

This is an important clinical point that linear modeling may not be able to adequately address, as also pointed out by a previous study, ${ }^{31}$ that suggests the change in motor FIM score would be best represented by a decelerating function with a plateau. Further, this nonlinear relationship between hours of therapy and motor functional change highlights the importance of monitoring patients' functional ability throughout the rehabilitation process so that the therapeutic program can be modified accordingly to achieve optimal allocation of resource and patient outcomes.

The nonlinear relationship between hours of therapy and motor functional change also suggests the possibility of therapy delivered earlier after injury being more effective than that delivered later after injury, implying the timing of therapy is important in predicting functional outcome. Because most improvements in neurorecovery are made during the first three months after $\mathrm{SCI},{ }^{32-35}$ early rehabilitation maximizes this window of opportunity leading to better short-term and long-term patient outcomes, ${ }^{6}$ as well as system outcomes such as LOS and FIM efficiency. ${ }^{36,37}$ In the future, if additional time points of motor FIM score throughout the rehabilitation LOS were collected, the impact of providing higher therapy intensity during the early phase of rehabilitation on patient outcome could be investigated.

Starting point of functional status. Relative changes in motor FIM efficiency should be considered for all groups, especially the high cervical AIS A,B,C group. Our simulation scenario showed that this group had the smallest absolute gain compared with other groups, but their relative change was similar to that of other groups, illustrating that the starting point and the potential to improve in relation to the starting point are important factors to consider.

Impact of therapy intensity. A previous study has shown that increasing therapy intensity by as little as less than $1 \mathrm{~h}$ a day could significantly reduce LOS in the rehabilitation for stroke, orthopedic, and other impairments. ${ }^{13}$ According to a recent economic analysis on the cost-effectiveness of inpatient rehabilitation after stroke, the reduction in LOS that results from providing higher therapy intensity can offset the additional PT hours needed. ${ }^{38}$

Our analysis of the hypothetical increases in therapy intensity is suggestive of the potential financial benefits related to LOS and services; however, further consideration of resources needed to provide the increased therapy intensity is necessary to assess the net benefits of these hypothetical changes. Further, understanding the impact of therapy intensity and the factors related to therapy intensity might help with identifying optimal feasibility. It has been shown that the clinician's expectation and experience correspond to higher therapy intensity; while comorbidities, older age, and ventilator use at rehabilitation admission are associated with lower therapy intensity. ${ }^{39}$ Patients' ability and willingness to participate in longer hours of therapy also deserve consideration in the feasibility of modulating the therapy.

\section{Limitations}

The analysis in this study utilized data collected from a single site that had a limited representation of patients with $\mathrm{C} 1-3$ necessitating ventilation support. The study cohort may not be representative of the entire patient population from the study site, because those with incomplete data were significantly different 
from the study cohort as shown by the sensitivity analysis. There might be other potential biases using retrospective data.

The clinical application of our results remains to be tested, because the minimal clinical significant improvement in motor FIM has not been determined. Further, motor FIM used as the outcome measure is a valid measure of burden of care and not necessarily of functional recovery. Goals other than those measured by motor FIM and those attributed by other disciplines such as social work and psychology were not assessed in this study, but they all contribute to the effectiveness of rehabilitation, particularly the social integration and recovery of the patients.

The contents or certain activities within the therapy hours reported here were not considered. Data on pre-existing comorbidities were not available, but given that comorbidities can limit rehabilitation, their potential effect on motor FIM change remains to be explored. ${ }^{6,40}$ In addition, data collected spanned over seven years during which the mean total hours of therapy provided and the mean motor FIM change of patients had remained relatively steady; however, changes in medical attention, rehabilitation treatments of SCI, and FIM scoring could still have confounded the results.

As for the simulation model, the assumption of the fixed motor FIM change regardless of the time it takes to deliver a fixed certain amount of therapy was made because there was limited empirical evidence on spontaneous recovery and on comparing patients receiving therapy at different intensities. Further, the care costs were based on a study on economic burden of tSCI in Canada and were to provide a general estimate on the financial implication of tSCI care.

\section{Conclusion}

This study explored the effect of amount and intensity of therapy provided to persons with tSCI on motor functional change and system outcomes. We found that amount of therapy was positively associated with motor functional change in a nonlinear fashion and that raising the amount of therapy received through therapy intensity increase could lead to reduced resource utilization and cost savings. The results highlight the importance of monitoring patients' functional change throughout rehabilitation and also the need for a different strategy for persons with poor outcomes prognosis.

\section{Acknowledgments}

The authors thank Kristen Walden, Anne Harris, Barry White, Luc Noreau, Julie Beaulieu, Isabelle Cote, Jacynthe Giguere, and Valerie Lemay for advice; and the Institut de réadaptation en déficience physique de Québec for their contribution to the study.

This study was supported by financial contributions from the Rick Hansen Institute, the Ontario Neurotrauma Foundation, and the Government of Canada through Health Canada and Western Economic Diversification Canada.

\section{Author Disclosure Statement}

No competing financial interests exist.

\section{References}

1. Heinemann, A.W. (2007). State-of-the-science on postacute rehabilitation: setting a research agenda and developing an evidence base for practice and public policy. An introduction. Arch. Phys. Med. Rehabil. 86, 869-874.

2. Heinemann, A.W., Linacre, J.M., Wright, B.D., Hamilton, B.B., and Granger, C. (1994). Prediction of rehabilitation outcomes with disability measures. Arch. Phys. Med. Rehabil. 75, 133-143.
3. Heinemann, A.W., Hamilton, B., Linacre, J.M., Wright, B.D., and Granger, C. (1995). Functional status and therapeutic intensity during inpatient rehabilitation. Am. J. Phys. Med. Rehabil. 74, 315-326.

4. Hsieh, C.H., DeJong, G., Groah, S., Ballard, P.H., Horn, S.D., and Tian, W. (2013). Comparing rehabilitation services and outcomes between older and younger people with spinal cord injury. Arch. Phys. Med. Rehabil. 94, Suppl, S175-S186.

5. Al-Habib, A.F., Attabib, N., Ball, J., Bajammal, S., Casha, S., and Hurlbert, R.J. (2011). Clinical predictors of recovery after blunt spinal cord trauma: systematic review. J. Neurotrauma 28, 1431-1443.

6. Whiteneck, G., Gassaway, J., Dijkers, M.P., Heinemann, A.W., and Kreider, S.E. (2012). Relationship of patient characteristics and rehabilitation services to outcomes following spinal cord injury: the SCIRehab project. J. Spinal Cord Med. 35, 484-502.

7. Ozelie, R., Gassaway, J., Buchman, E., Thimmaiah, D., Heisler, L., Cantoni, K., Foy, T., Hsieh, C.H., Smout, R.J., Kreider, S.E., and Whiteneck, G. (2012). Relationship of occupational therapy inpatient rehabilitation interventions and patient characteristics to outcomes following spinal cord injury: the SCIRehab project. J. Spinal Cord Med. 35, 527-546.

8. Teeter, L., Gassaway, J., Taylor, S., LaBarbera, J., McDowell, S., Backus, D., Zanca, J.M., Natale, A., Cabrera, J., Smout, R.J., Kreider, S.E., and Whiteneck, G. (2012). Relationship of physical therapy inpatient rehabilitation interventions and patient characteristics to outcomes following spinal cord injury: the SCIRehab project. J. Spinal Cord Med. 35, 503-526.

9. Chen, C.C., Heinemann, A.W., Granger, C. V, and Linn, R.T. (2002). Functional gains and therapy intensity during subacute rehabilitation: a study of 20 facilities. Arch. Phys. Med. Rehabil. 83, 1514-1523.

10. Graves, D.E., Frankiewicz, R.G., and Carter, R.E. (1999). Gain in functional ability during medical rehabilitation as related to rehabilitation process indices and neurologic measures. Arch. Phys. Med. Rehabil. 80, 1464-1470.

11. Slade, A., Tennant, A., and Chamberlain, M.A. (2002). A randomised controlled trial to determine the effect of intensity of therapy upon length of stay in a neurological rehabilitation setting. J. Rehabil. Med. 34, 260-266.

12. Kwakkel, G., van Peppen, R., Wagenaar, R.C., Wood Dauphinee, S., Richards, C., Ashburn, A., Miller, K., Lincoln, N., Partridge, C., Wellwood, I., and Langhorne, P. (2004). Effects of augmented exercise therapy time after stroke: a meta-analysis. Stroke 35, 2529-2539.

13. Jette, D.U., Warren, R.L., and Wirtalla, C. (2005). The relation between therapy intensity and outcomes of rehabilitation in skilled nursing facilities. Arch. Phys. Med. Rehabil. 86, 373-379.

14. Johnston, M.V, and Miller, L.S. (1986). Cost-effectiveness of the Medicare three-hour regulation. Arch. Phys. Med. Rehabil. 67, 581-585.

15. Ahn, H., Lewis, R., Santos, A., Cheng, C.L., Noonan, V.K., Dvorak, M.F., Singh, A., Linassi, A.G., Christie, S., Goytan, M., and Atkins, D. (2017). Forecasting financial resources for future traumatic spinal cord injury care using simulation modeling. J. Neurotrauma [Epub ahead of print; PMID 28594315].

16. Hirsch, G., Homer, J., Evans, E., and Zielinski, A. (2010). A system dynamics model for planning cardiovascular disease interventions. Am. J. Public Health 100, 616-622.

17. Atun, R.A., Lebcir, R., Drobniewski, F., and Coker, R.J. (2005). Impact of an effective multidrug-resistant tuberculosis control programme in the setting of an immature HIV epidemic: system dynamics simulation model. Int. J. STD AIDS 16, 560-570.

18. Curry, J., Fitzgerald, A., Prodan, A., Dadich, A., and Sloan, T. (2014). Combining patient journey modelling and visual multi-agent computer simulation: A framework to improving knowledge translation in a healthcare environment. Stud. Health Technol. Inform. 204, 25-31.

19. Zhou, H., Isaman, D.J., Messinger, S., Brown, M.B., Klein, R., Brandle, M., and Herman, W.H. (2005). A computer simulation model of diabetes progression, quality of life, and cost. Diabetes Care 28, 2856-2863.

20. Atkins, D., Noonan, V.K., Santos, A., Lewis, R., Fehlings, M., Burns, A., and Dvorak, M. (2012). Secondary complications in SCI across the continuum: Using operations research to predict the impact and optimize management strategies. Top. Spinal Cord Inj. Rehabil. 18, 57-66.

21. Noonan, V.K., Soril, L., Atkins, D., Lewis, R., Santos, A., Fehlings, M.G., Burns, A.S., Singh, A., and Dvorak, M.F. (2012). The application of operations research methodologies to the delivery of care model for traumatic spinal cord injury: the access to care and timing project. J. Neurotrauma 29, 2272-2282. 
22. Santos, A., Gurling, J., Dvorak, M.F., Noonan, V.K., Fehlings, M.G., Burns, A.S., Lewis, R., Soril, L., Fallah, N., Street, J.T., Bélanger, L., Townson, A., Liang, L., and Atkins, D. (2013). Modeling the patient journey from injury to community reintegration for persons with acute traumatic spinal cord injury in a Canadian centre. PLoS One 8, e72552.

23. Kirshblum, S.C., Waring, W., Biering-Sorensen, F., Burns, S.P., Johansen, M., Schmidt-Read, M., Donovan, W., Graves, D., Jha, A., Jones, L., Mulcahey, M.J., and Krassioukov, A. (2011). Reference for the 2011 revision of the International Standards for Neurological Classification of Spinal Cord Injury. J. Spinal Cord Med. 34, 547-554.

24. Hastie, T., and Tibshirani, R. (1990). Exploring the nature of covariate effects in the proportional hazards model. Biometrics 46, 1005-1016.

25. Krueger, H., Noonan, V.K., Trenaman, L.M., Joshi, P., and Rivers, C.S. (2013). The economic burden of traumatic spinal cord injury in Canada. Chronic Dis. Inj. Can. 33, 113-122.

26. Consortium for Spinal Cord Medicine. (2000). Outcomes following traumatic spinal cord injury: clinical practice guidelines for healthcare professionals. J Spinal Cord Med. 23, 289-316.

27. McKinley, W., Sinha, A., Ketchum, J., and Deng, X. (2011). Comparison of rehabilitation outcomes following vascular-related and traumatic spinal cord injury. J. Spinal Cord Med. 34, 410-415.

28. McKinley, W., Meade, M.A., Kirshblum, S., and Barnard, B. (2004). Outcomes of early surgical management versus late or no surgical intervention after acute spinal cord injury. Arch. Phys. Med. Rehabil. $85,1818-1825$.

29. Adler, C. (1996). Spinal cord injury, in: Occupational Therapy Practice Skills for Physical Dysfunction, 4th ed. Lorraine Williams Pedretti (ed). Chicago: Mosby, pps. 765-784.

30. White, M.G., and Hawn, M. (1989). Functional Goals at Specific Levels of Spinal Cord Injury, 1st ed. Englewood, CO: Craig Hospital.

31. Warschausky, S., Kay, J.B., and Kewman, D.G. (2001). Hierarchical linear modeling of FIM instrument growth curve characteristics after spinal cord injury. Arch. Phys. Med. Rehabil. 82, 329-334.

32. Waters, R.L., Adkins, R.H., Yakura, J.S., and Sie, I. (1994). Motor and sensory recovery following incomplete paraplegia. Arch. Phys. Med. Rehabil. 75, 67-72.
33. Waters, R.L., Yakura, J.S., Adkins, R.H., and Sie, I. (1992). Recovery following complete paraplegia. Arch. Phys. Med. Rehabil. 73, 784789.

34. Waters, R.L., Adkins, R.H., Yakura, J.S., and Sie, I. (1994). Motor and sensory recovery following incomplete tetraplegia. Arch. Phys. Med. Rehabil. 75, 306-311.

35. Waters, R.L., Adkins, R.H., Yakura, J.S., and Sie, I. (1993). Motor and sensory recovery following complete tetraplegia. Arch. Phys. Med. Rehabil. 74, 242-247.

36. Sumida, M., Fujimoto, M., Tokuhiro, A., Tominaga, T., Magara, A., and Uchida, R. (2001). Early rehabilitation effect for traumatic spinal cord injury. Arch. Phys. Med. Rehabil. 82, 391-395.

37. DeVivo, M.J., Kartus, P.L., Stover, S.L., and Fine, P.R. (1990). Benefits of early admission to an organised spinal cord injury care system. Paraplegia 28, 545-555.

38. Chan, B. (2015). Effect of increased intensity of physiotherapy on patient outcomes after stroke: an economic literature review and costeffectiveness analysis. Ont. Health Technol. Assess. Ser. 15, 1-43.

39. Whiteneck, G., Gassaway, J., Dijkers, M., Backus, D., Charlifue, S., Chen, D., Hammond, F., Hsieh, C.H., and Smout, R.J. (2011). The SCIRehab project: treatment time spent in SCI rehabilitation. Inpatient treatment time across disciplines in spinal cord injury rehabilitation. J. Spinal Cord Med. 34, 133-148.

40. Horn, S.D., Smout, R.J., DeJong, G., Dijkers, M.P., Hsieh, C.H., Lammertse, D., and Whiteneck, G.G. (2013). Association of various comorbidity measures with spinal cord injury rehabilitation outcomes. Arch. Phys. Med. Rehabil. 94, Suppl, S75-S86.

Address correspondence to: Catherine Truchon, PhD, MScAdm Institut national d'excellence en santé et en services sociaux 2535 boul Laurier, 5ème étage Québec City, Québec G1V $4 M 3$ Canada

E-mail: catherine.truchon@inesss.qc.ca 